\title{
Membrane lipid composition and invertase secretion of Neurospora crassa and its wall-less mutant slime: effects of temperature and the surfactant Tween 80
}

\author{
Marcelo Buzzi, ${ }^{\dagger} \dagger$ Maria Sueli Soares Felipe, Maristella de Oliveira Azevedo \\ and RuY de ARaujo Caldas
}

Departamento de Biologia Celular, Instituto de Ciencias Biologicas, Universidade de Brasilia, Brasilia, 70 910, D.F., Brazil

(Received 9 December 1992; revised 8 March 1993; accepted 15 March 1993)

\begin{abstract}
The effects of temperature and the surfactant Tween 80 on the secretion of invertase by the ascomycete fungus Neurospora crassa and its wall-less strain slime were investigated. Temperature acclimation dramatically affects the phospholipid fatty acid pattern in both strains. The levels of polyunsaturated fatty acids in membrane lipids of wild-type Neurospora crassa and slime increased as growth temperature decreased. Chromatogram analysis from cultures acclimated to $15^{\circ} \mathrm{C}$ showed high levels of linolenic acid (18:3), and low levels of oleic acid (18:1), suggesting desaturation. Reducing the temperature during growth to $15^{\circ} \mathrm{C}$ affected phospholipid fatty acid composition in both strains, which resulted in a higher level of invertase secretion. The wild-type Neurospora crassa showed no difference in invertase secretion in the presence of Tween 80 . However, the addition of the surfactant to slime cultures caused a $60 \%$ increase in invertase secretion, which was more evident after $48 \mathrm{~h}$ incubation.
\end{abstract}

\section{Introduction}

During the last 20 years, the slime has been considered one of the most intriguing morphological mutants of the filamentous fungus Neurospora crassa. The slime cultures develop as osmotically sensitive spheroplasts, exhibiting a deficiency in cell wall morphogenesis and in the control of the release of many exoenzymes (Pietro et al., 1989).

The physical properties of the membrane, such as cell permeability and fluidity, are mostly determined by the phospholipids therein, the fatty acid composition of these phospholipids, and their interaction with cholesterol, enzymes and proteins of the cytoskeletal material (Bell et al., 1986). In relation to fatty acid composition, it is often assumed that membrane fluidity and fatty acid unsaturation are related in a simple and direct manner, so that an increase in unsaturation is taken to imply increased membrane fluidity (Bell et al., 1986). The temperature strongly influences membrane fluidity since the physical properties of the lipids therein are temperature-dependent (Skriver \& Thompson, 1976). It is known that many organisms, including $N$. crassa, can

\footnotetext{
*Author for correspondence. Present address: NERC Unit of Aquatic Biochemistry, Department of Biological and Molecular Science, University of Stirling, Stirling FK9 4LA, UK.
}

vary their membrane lipid composition in response to changing temperature (Hunter \& Rose, 1971; Fukushima et al., 1976; Martin et al., 1981). N. crassa cultures acclimated from 37 to $15^{\circ} \mathrm{C}$ showed high levels of unsaturated fatty acids in their membranes, indicating that membrane fluidity is regulated with respect to growth temperature through changes in membrane lipid composition (Martin et al., 1981). Yazdi et al. (1990) have demonstrated recently that the secretion of several cellulolytic enzymes of $N$. crassa is intimately linked to membrane lipid composition, and the increased release of these enzymes can be justified through the alteration of membrane fluidity by the increased unsaturation of the lipids.

Previous experiments on fungal cell permeability demonstrated that non-ionic surfactants can stimulate the release of enzymes (Reese \& Maguire, 1969). Tests conducted on the cellulase complex of $N$. crassa showed that the surfactant Tween 80 was effective in stimulating the induction and secretion of enzymes (Yazdi et al., 1990). To extend our studies in $N$. crassa enzyme secretion, we therefore considered it interesting to examine the effects of temperature on the phospholipid fatty acid composition from wild-type and slime strains. The influence of the surfactant Tween 80 on membrane permeability was also investigated in both strains. 


\section{Methods}

$N$. crassa strains and culture conditions. Two strains of $N$. crassa were utilized: FGSC 424a (wild-type) and FGSC 1118 (slime) from the Fungal Genetic Stock Center (Kansas City, KS, USA). Wild-type stock cultures were maintained on $20 \mathrm{ml}$ solid Vogel's minimal medium $(2 \%$, $\mathrm{w} / \mathrm{v}$, sucrose and $2 \%, \mathrm{w} / \mathrm{v}$, agar; Vogel, 1964) in $100 \mathrm{ml}$ conical flasks. Slime stock cultures were grown on $20 \mathrm{ml}$ slants containing $5 \mathrm{ml}$ solid Vogel's minimal medium supplemented with $0.75 \%$ peptone, and $0.75 \%$ yeast extract. Experimental cultures for both strains were grown in $250 \mathrm{ml}$ conical flasks containing $50 \mathrm{ml}$ Vogel's liquid medium (minimal medium) supplemented with $0.75 \%$ peptone, $0.75 \%$ yeast extract and $0.5 \mathrm{M}$-sorbitol. Before autoclaving $0.2 \%$ Tween 80 (polyoxyethylene sorbitan monooleate) was added to flasks. The inoculum consisted of a suspension of 5-d-old conidia to give a final concentration of $10^{7}$ conidia $\mathrm{ml}^{-1}$. The inocula of the slime cultures were prepared by suspending 3-d-old spheroplasts in $0.5 \mathrm{M}$-sorbitol from a growth slant culture at a concentration of $5.0 \times 10^{6}$ spheroplasts $\mathrm{ml}^{-1}$. Cultures were grown in a rotary shaker $\left(120\right.$ r.p.m.) at $30^{\circ} \mathrm{C}$ for $48 \mathrm{~h}$. In temperature shift growth tests, the cultures were first grown at $30^{\circ} \mathrm{C}$ for $24 \mathrm{~h}$ and then transferred to $15^{\circ} \mathrm{C}$ for another $24 \mathrm{~h}$. Mycelial pads were harvested by filtration and slime spheroplasts centrifuged at appropriate times before freeze drying to determine the dry weight for further lipid analysis. The supernatants were saved for enzyme determination.

Enzyme assay. The supernatants were dialysed overnight at $4^{\circ} \mathrm{C}$ and invertase specific activity determined according to Arnold (1974). One enzyme unit is defined as the amount of enzyme which catalyses the hydrolysis of $1 \mu \mathrm{mol}$ sucrose $\min ^{-1}$ at $30^{\circ} \mathrm{C}$ and $\mathrm{pH} \mathrm{5.5}$. The incubations were started by adding the sucrose in acetate buffer to the dialysed suspensions from slime and wild-type $N$. crassa cultures. After $30 \mathrm{~min}$ the reaction was stopped by the addition of dinitrosalicylic acid reagent, and reducing sugars were determined spectrophotometrically. The control for each enzyme assay was performed by adding the culture suspension, previously heated to $100^{\circ} \mathrm{C}$, to the sucrose. Specific activities were expressed as units (mg dry wt $)^{-1}$.

Lipid extraction and analysis. Lipids were extracted from freeze dried mycelial pads and slime spheroplasts according to a modified procedure of Folch et al. (1957) described by Christie (1982). Phospholipids were separated from neutral lipids by thin layer chromatography (TLC) on silica Type $G$ plates $(0.25 \mathrm{~mm})$ that had been pre-run in diethyl ether and activated at $110^{\circ} \mathrm{C}$ for $1 \mathrm{~h}$. The plates were developed in hexane/diethyl ether/glacial acetic acid $(80: 20: 2$, by vol.) to separate phospholipids from neutral lipids running at the solvent front. Separated lipid classes were identified by spraying the developed chromatograms with $2^{\prime}, 7^{\prime}$-dichlorofluorescein in $97 \%(\mathrm{v} / \mathrm{v})$ methanol. The phospholipid bands were visualized under UV light and scraped into test tubes. A solution of hexane/methanol $(1: 1, \mathrm{v} / \mathrm{v})$ was added to extract the phospholipids from the silica. The phospholipids were then esterified by adding a fresh solution of $1 \%(\mathrm{v} / \mathrm{v})$ sulphuric acid in methanol and incubated for $16 \mathrm{~h}$ at $50^{\circ} \mathrm{C}$ (Christie, 1982). All solvents contained $0.05 \%$ butylated hydroxytoluene (BHT) as antioxidant. The fatty acid methyl esters were extracted with hexane and analysed on a gas chromatograph (Varian, Model 3300) equipped with a flame ionization detector $\left(300^{\circ} \mathrm{C}\right)$, and an on-column injector $\left(250^{\circ} \mathrm{C}\right)$, and fitted with a fused silica capillary column ( $30 \mathrm{~m} \times 0.52 \mathrm{~mm}$ Megabore $\mathrm{J}$ $\& \mathrm{~W})$. The carrier gas was nitrogen at a pressure of 5 p.s.i. $(34.5 \mathrm{kPa})$, and the temperature programme adjusted from 50 to $160^{\circ} \mathrm{C}$ at a rate of $39^{\circ} \mathrm{C} \mathrm{min}-1$, and then from 160 to $235^{\circ} \mathrm{C}$ at a rate of $2^{\circ} \mathrm{C} \mathrm{min}-1$. Peak identification was determined by comparison with reference standards and a reference sample. Computation of the peaks and identification were achieved on a recording integrator (Varian 4290).

Statistical analysis. All results are the means of three experiments \pm SD. The data contained in Tables 1-3 were subjected to two-way analysis of variance (ANOVA) performed by StatWorks 1.2 (Cricket Software Inc., Philadelphia, PA, USA) for Apple Computers. This allowed comparisons of wild-type $N$. crassa and slime strains with regard to differences in fatty acid composition and invertase activity at different temperatures, and differences in invertase activity with Tween 80 . The differences are reported in the text and Tables as significant if $P<0.05$.

Materials. BHT, sorbitol, Tween 80 , sucrose, Silica Type $\mathrm{G}$ and dinitrosalicylic acid were all obtained from Sigma. Peptone of casein, yeast extract and agar were all obtained from Biobrás (Montes Claros MG, Brazil). 2', 7'-Dichlorofluorescein was obtained from Aldrich and all the solvents were from Merck.

\section{Results}

Enzyme assays showed that the specific activity of extracellular invertase in slime cultures (FGSC 1118) was at least 100 times higher than in the wild-type $N$. crassa. This hypersecretion of invertase by the slime strain has been reported by other authors (Gratzner \& Sheenan, 1969; Lampen, 1971; Bigger et al., 1972; Pietro et al., 1989).

\section{Invertase specific activity with respect to growth temperature}

If membrane fluidity depends on the high levels of the unsaturated phospholipid fatty acids, we would expect to find membranes more fluid in cultures transferred to low temperatures, since it is well known that the degree of unsaturation in fatty acids increases with decreasing growth temperature. To test this possibility, cultures of wild-type $N$. crassa and slime were grown first at $30^{\circ} \mathrm{C}$, transferred to $15^{\circ} \mathrm{C}$ and then reincubated at $30^{\circ} \mathrm{C}$ to

Table 1. Specific activity of extracellular invertase from wild-type $N$. crass a and slime previously acclimated to $15^{\circ} \mathrm{C}$ and incubated at $30^{\circ} \mathrm{C}$

\begin{tabular}{lccc}
\hline \hline Strain & $\begin{array}{c}\text { Incubation } \\
\text { period* } \\
\text { (min) }\end{array}$ & $\begin{array}{c}\text { Acclimation } \\
\text { conditions } \dagger\end{array}$ & $\begin{array}{c}\text { Specific activity } \\
\text { [units (mg dry wt) }\end{array}$ \\
\hline Wild-type & 90 & $a$ & $0.001 \pm 0.001$ \\
Slime & 90 & $b$ & $0.005 \pm 0.003$ \\
& 30 & $a$ & $0.388 \pm 0.039 \S$ \\
& 30 & $b$ & $0.580 \pm 0.017 \S$ \\
& 90 & $a$ & $0.928 \pm 0.073$ \\
& 90 & $b$ & $1.078 \pm 0.094$ \\
& 180 & $a$ & $1.214 \pm 0.005$ \\
& 180 & $b$ & $1.027 \pm 0.218$ \\
\hline \hline
\end{tabular}

*After acclimation procedure

$\uparrow$ Conditions: (a) cultures grown at $30^{\circ} \mathrm{C}$ for $48 \mathrm{~h}$ (control); (b) cultures grown at $30^{\circ} \mathrm{C}$ for $24 \mathrm{~h}$ and transferred to $15^{\circ} \mathrm{C}$ for another $24 \mathrm{~h}$.

$\ddagger$ Specific activity values of extracellular invertase are means \pm SD $(n=3)$.

$\S$ The values under condition $(a)$ were significantly different $(P<0.05)$ from condition $(b)$. 
Table 2. Phospholipid fatty acid composition of wild-type N. crassa and slime grown at $30^{\circ} \mathrm{C}$ and transferred to $15^{\circ} \mathrm{C}$

Each value is the mean weight $\%$ of the total fatty acid \pm SD of three independent experiments. Fatty acid species which were in all cases less than $1 \%$ are not shown $(\mathrm{r})$. Conditions $(a)$ and (b) are as described in Table 1.

\begin{tabular}{|c|c|c|c|c|}
\hline \multirow[b]{2}{*}{ Fatty acid } & \multicolumn{2}{|c|}{ Wild-type } & \multicolumn{2}{|c|}{ Slime } \\
\hline & $a$ & $b$ & $a$ & $b$ \\
\hline $15: 0-$ & $1.6 \pm 0.4$ & $\mathbf{r}$ & $1.3 \pm 0.5$ & $\mathbf{r}$ \\
\hline 16:0 Palmitic acid & $20 \cdot 3 \pm 2 \cdot 4$ & $15 \cdot 5 \pm 1 \cdot 8$ & $13 \cdot 2 \pm 1 \cdot 1$ & $12 \cdot 9 \pm 0 \cdot 7$ \\
\hline 16:1 Palmitoleic acid & $2 \cdot 3 \pm 0.8$ & $1.5 \pm 0.3$ & $3.8 \pm 0.4$ & $2 \cdot 5 \pm 0.3$ \\
\hline 18:0 Stearic acid & $1.8 \pm 0.3$ & $1 \cdot 3 \pm 0 \cdot 2$ & $1 \cdot 2 \pm 0 \cdot 2$ & $1.5 \pm 0.5$ \\
\hline 18:1 Oleic acid & $18 \cdot 8 \pm 2 \cdot 2$ & $5 \cdot 8 \pm 0.9$ & $27 \cdot 6 \pm 0 \cdot 3$ & $6 \cdot 3 \pm 1 \cdot 2$ \\
\hline 18:2 Linoleic acid & $46 \cdot 8 \pm 3 \cdot 5$ & $35 \cdot 7 \pm 1 \cdot 8$ & $37 \cdot 1 \pm 0 \cdot 8$ & $33 \cdot 2 \pm 2 \cdot 0$ \\
\hline 18:3 Linolenic acid & $7 \cdot 5 \pm 1 \cdot 3$ & $36 \cdot 4 \pm 2 \cdot 4$ & $13.5 \pm 1.3$ & $40 \cdot 8 \pm 2 \cdot 4$ \\
\hline$\Sigma$ Saturates & $2 \overline{3} \cdot 7$ & $1 \overline{6} \cdot 8$ & $1 \overline{5 \cdot 7}$ & $1 \overline{4} \cdot 4$ \\
\hline$\Sigma$ Monosaturates & $21 \cdot 1$ & $7 \cdot 3$ & $31 \cdot 4$ & $8 \cdot 8$ \\
\hline$\Sigma$ Polyunsaturates & $54 \cdot 3$ & $72 \cdot 1$ & $50 \cdot 6$ & $74 \cdot 0$ \\
\hline
\end{tabular}

observe invertase secretion. In fact, cultures transferred from 30 to $15^{\circ} \mathrm{C}$ showed higher invertase activity than the control grown only at $30^{\circ} \mathrm{C}$ (Table 1 ). The results in Table 1 show that after 30 min incubation the activity of extracellular invertase of the slime cultures acclimated to $15^{\circ} \mathrm{C}$ was significantly higher (ANOva, $P<0.05$ ) than in the control (grown only at $30^{\circ} \mathrm{C}$ ). After $90 \mathrm{~min}$ incubation the invertase specific activity in acclimated slime cultures stayed slightly higher, but not significantly different from the control. In contrast, the cultures of wild-type $N$. crassa acclimated to $15^{\circ} \mathrm{C}$ showed no significant difference in invertase activity over the same period of incubation. After $180 \mathrm{~min}$ incubation neither acclimated slime nor wild-type $N$. crassa showed differences in invertase activity compared to the control.

\section{Phospholipid fatty acid composition with respect to growth temperature}

Previous experiments with $N$. crassa have shown that phospholipid fatty acids increased in unsaturation with decreasing temperature (Martin et al., 1981). The results shown in Table 2 are in agreement with those of Martin et al. (1981). The major phospholipid fatty acids in both strains are molecules of 18 carbons, such as oleic (18:1), linoleic (18:2) and linolenic acid (18:3). The data show that the total percentage of these fatty acids varies with decreasing growth temperature. Table 2 shows that a temperature shift from 30 to $15^{\circ} \mathrm{C}$ resulted in a striking increase of linolenic acid (18:3) in both strains, fourfold in the slime and threefold in wild-type $N$. crassa. The results also show that this increment of $18: 3$ was followed by a corresponding decline of oleic acid (18:1) in both strains, which indicates that cultures acclimated to $15^{\circ} \mathrm{C}$ produced high levels of unsaturated fatty acids, pre- sumably by the increase of desaturase activity. There is a similar, although much smaller, decline in the level of linoleic acid (18:2), palmitic acid (16:0) and 15:0 with decreasing growth temperature over the same range.

\section{Effect of surfactant Tween 80}

To test the effect of surfactants on the cell permeability of wild-type $N$. crassa and slime, we added Tween 80 to the cultures, based on the fact that it is the most effective surfactant in stimulating enzyme secretion in fungi (Reese \& Maguire, 1969; Yazdi et al., 1990). The effect of Tween 80 on the specific activity of extracellular invertase from wild-type $N$. crassa and slime is shown in Table 3. The data show that the addition of $0.2 \%$ Tween 80 to slime cultures resulted in a significant increase (ANOVA, $P<0.05)$ in invertase activity $(60 \%)$ after $48 \mathrm{~h}$ incubation at $30^{\circ} \mathrm{C}$. Slime cultures grown only for $24 \mathrm{~h}$

Table 3. Effect of Tween $80(0 \cdot 2 \%)$ on the activity of extracellular invertase from wild-type $N$. crassa and slime grown at $30^{\circ} \mathrm{C}$

\begin{tabular}{|c|c|c|}
\hline $\begin{array}{l}\text { Strain/incubation } \\
\text { period (h) }\end{array}$ & Medium & $\begin{array}{c}\text { Specific activity* } \\
\left.[\text { units (mg dry wt })^{-1}\right]\end{array}$ \\
\hline Wild-type/24 & $\begin{array}{l}\text { - Tween } 80 \\
\text { + Tween } 80\end{array}$ & $\begin{array}{l}0.046 \pm 0.002 \\
0.065 \pm 0.041\end{array}$ \\
\hline Wild-type/48 & $\begin{array}{l}\text { - Tween } 80 \\
\text { + Tween } 80\end{array}$ & $\begin{array}{l}0.080 \pm 0.049 \\
0.054 \pm 0.005\end{array}$ \\
\hline Slime $/ 24$ & $\begin{array}{l}\text { - Tween } 80 \\
\text { + Tween } 80\end{array}$ & $\begin{array}{l}20.49 \pm 6.057 \\
18.89 \pm 6.802\end{array}$ \\
\hline Slime $/ 48$ & $\begin{array}{l}\text {-Tween } 80 \\
+ \text { Tween } 80\end{array}$ & $\begin{array}{l}27.07 \pm 2.045 \dagger \\
43.41 \pm 2.673 \dagger\end{array}$ \\
\hline
\end{tabular}

* Specific activity values are means \pm SD $(n=3)$.

$\dagger$ Invertase activity with Tween 80 was significantly different $(P<0.05)$ from the control (without Tween 80). 
showed no difference in activity when Tween 80 was added to the culture medium. The results in Table 3 show also that wild-type $N$. crassa did not respond to the presence of the surfactant.

\section{Discussion}

Previous experiments have demonstrated that the slime strain of $N$. crassa, defective in cell wall morphogenesis, exhibits a hypersecretion capacity for invertase compared to the wild-type strain (Bigger et al., 1972; Gratzner \& Sheenan, 1969; Lampen, 1971; Pietro et al., 1989). Bigger et al. (1972) reported that the invertase secreted by the slime strain (FGSC 1118) was serologically similar to that secreted by wild-type $N$. crassa. The slime strain can secrete to the medium $95 \%$ of the total invertase synthesized, in contrast to the wild-type strain that retains most of the enzyme internally. Pietro et al. (1989) demonstrated that the slime strain produces invertase constitutively due to a pleiotropic deficiency in the regulation of invertase catabolism.

The results presented here show clearly that temperature affects enormously the phospholipid fatty acid composition in $N$. crassa strains. Decreasing the culture temperature from 30 to $15^{\circ} \mathrm{C}$ demonstrated that these organisms respond to these conditions by enhancing the levels of polyunsaturated fatty acids in membrane lipids with a consequent increase in enzyme secretion. Many organisms are well known for responding to temperature variations by changing their membrane fatty acid composition (Hunter \& Rose, 1971; Fukushima et al., 1975; Martin et al., 1981). Experiments using the yeast Saccharomyces cerevisiae demonstrated that decreasing temperatures in batch cultures was accompanied by an increase of unsaturation in membrane phospholipids (Hunter \& Rose, 1971). Fukushima et al. (1975) reported that the membrane of Tetrahymena pyriformis served as a reservoir of fatty acid substrate for desaturation and formation of more polyunsaturated lipids when the temperature was lowered to $15^{\circ} \mathrm{C}$. Experiments on the effects of temperature acclimation on $N$. crassa phospholipids showed that linolenic acid (18:3) dramatically increased with decreasing growth temperature, indicating that membrane fluidity is regulated through changes in membrane lipid composition (Martin et al., 1981). The results of this paper are in agreement with those from Martin et al. (1981), since linolenic acid (18:3) increased several times when wild-type and slime cultures were transferred from 30 to $15^{\circ} \mathrm{C}$. The corresponding decline of the levels of oleic acid $(18: 1)$, palmitic acid $(16: 0)$ and 15:0 with decreasing temperature is strong evidence that these fatty acids served as a substrate for desaturation to increase the levels of unsaturated fatty acids in such a way that membrane fluidity is restored to a functional level. Martin et al. (1981) suggested that 15-desaturase is probably the enzyme responsible for large changes in linolenic acid (18:3) in membrane lipids. The data from Tables 1 and 2 show that there is a close correlation between fatty acid unsaturation and invertase secretion in slime, indicating that the alterations in membrane phospholipid composition contributes to enzyme release even though the organisms are deficient in controlling enzyme production and secretion.

The purpose of adding Tween 80 in $N$. crassa cultures was to emphasize the value of this surfactant for increasing invertase yields. The data show that the addition of Tween 80 to slime cultures promoted a $60 \%$ increase in specific activity of extracellular invertase. Since the growth rate was not altered by the presence of Tween 80 , we suggest that this surfactant is only interfering with cell permeability. Reese \& Maguire (1968) demonstrated that Tween 80 can stimulate enzyme production in many fungi by promoting both entrance and exit of compounds from the cell. Recent experiments using $N$. crassa demonstrated that Tween 80 was the most effective surfactant in stimulating the release of enzymes of the cellulase complex (Yazdi et al., 1990). Although invertase secretion was not stimulated by Tween 80 in wild-type $N$. crassa as we reported here, other enzymes such as endoglucanase, exoglucanase and $\beta$-glucosidase can significantly increase their levels in the presence of this surfactant (Yazdi et al., 1990).

The authors would like to thank Dr Hector F. Terenzi for supplying the $N$. crassa strains, Dr Marilene Vainstein, and Dr Hugo Monteiro for their advice and help in performing invertase assays and TLC analysis. Our gratitude extends also to the researchers of Empresa Mogiana de Alimentos (Rações Guabi) for the support they have shown. This work was supported by grants from Conselho de Desenvolvimento Cientifico e Tecnologico (CNPq).

\section{References}

ARNold, W. N. (1974). Expression of cryptic fructofuranosidase in Saccharomyces rouxii. Journal of Bacteriology 120, 886-894.

Bell, M. V., Henderson, R. J. \& Sargent, J. R. (1986). The role of polyunsaturated fatty acids in fish. Comparative Biochemistry and Physiology 83B, 711-719.

BigGER, C. H., WhITE, M. R. \& BRAYMER, H. D. (1972). Ultrastructure and invertase secretion of the slime mutant of Neurospora crassa. Journal of General Microbiology 71, 159-166.

CHRIsTIE, W. W. (1982). The isolation of lipids from tissues. In Lipid Analysis, 2nd edn, pp. 17-23. Oxford: Pergamon Press.

FolCh, J., LeEs, M. \& StanLey, G. H. (1957). A simple method for the isolation and purification of total lipids from animal tissues. Journal of Biological Chemistry 226, 497-509.

Fukushima, H., Martin, C. E., IIDA, H., Kitajima, Y., Thompson, G. A., JR \& NozawA, Y. (1976). Changes in membrane lipid composition during temperature adaptation by a thermotolerant strain of Tetrahymena pyriformis. Biochimica et Biophysica Acta 431, 165-179.

GratzNER, H. G. \& Sheenan, D. N. (1969). Neurospora mutant exhibiting the hyperproduction of amylase and invertase. Journal of Bacteriology 97, 544-549.

HUNTER, K. \& Rose, A. H. (1972). Lipid composition of Saccharomyces 
cerevisiae as influenced by growth temperature. Biochimica et Biophysica Acta 260, 639-653.

LAMPEN, J. O. (1971). Yeast and Neurospora invertase. In The Enzymes, 3rd edn, vol. V, pp. 291-305. Edited by P. D. Boyer. New York: Academic Press.

Martin, C. E., Siegel, D. \& Aaronson, L. R. (1981). Effects of temperature acclimation on Neurospora phospholipids. Biochimica et Biophysica Acta 665, 399-407.

Pietro, R. C. L. R., Jorge, J. A. \& Terenzi, H. F. (1989). Pleiotropic deficiency in the control of carbon-regulated catabolic enzymes in the slime variant of Neurospora crassa. Journal of General Microbiology 135, 1375-1382.
ReEse, E. T. \& Maguire, A. (1969). Surfactants as stimulants of enzyme production by microorganisms. Applied Microbiology 17, 242-245.

SkRIVER, L. \& Thompson, G. A. JR (1979). Temperature-induced changes in fatty acid unsaturation of Tetrahymena membranes do not require induced fatty acid desaturase synthesis. Biochimica et Biophysica Acta 572, 376-381.

VoGEL, H. J. (1964). Distribution of lysine pathways among fungi: evolutionary implications. American Naturalist $98,435-446$.

YAZDI, M. T., WoODWARD, J. R. \& RADFORD, A. (1990). The cellulase complex of Neurospora crassa: activity, stability and release. Journal of General Microbiology 136, 1313-1319. 